\title{
Structure and function relationships of the respiratory muscles
}

\author{
J. Sauleda*, J. Gea**, M. Orozco-Levi**, J. Corominas+, J. Minguella*, C. Aguar**, \\ J. Broquetas**, A.G.N. Agustí*
}

Structure and function relationships of the respiratory muscles. J. Sauleda, J. Gea, M. Orozco-Levi, J. Corominas, J. Minguella, C. Aguar, J. Broquetas, A.G.N. Agustí. CERS Journals Ltd 1998.

ABSTRACT: Potential relationships between the structure of the diaphragm and external intercostals and several indices of respiratory muscle function, lung function and nutrition in 27 patients (61 \pm 10 yrs of age) subjected to thoracotomy as a result of a lung neoplasm have been investigated.

Prior to surgery the nutritional status of the patients was assessed and lung function (spirometry, lung volumes, transfer factor of the lungs for carbon monoxide, arterial blood gases) and respiratory muscle function (maximal inspiratory pressure (MIP) and diaphragmatic function were measured). Biopsies of the diaphragm (and external intercostals) were obtained during surgery.

On average, patients showed mild airflow limitation (forced expiratory volume in one second (FEV1), 70 $\pm 14 \%$ of predicted value, FEV1/forced vital capacity (FVC), $70 \pm 9 \%$ ) with some air trapping (residual volume (RV), $139 \pm 50 \%$ pred) and normal gas exchange (arterial oxygen tension $\left(P \mathrm{a}, \mathrm{O}_{2}\right), 11.3 \pm 1.33 \mathrm{kPa}(85 \pm 10 \mathrm{mmHg})$ ) and arterial carbon dioxide tension $\left(\mathrm{Pa}_{2} \mathrm{CO}_{2}\right) 5.4 \pm 0.5 \mathrm{kPa}(40.6 \pm 4 \mathrm{mmHg})$. MIP was $77 \pm 25 \%$ pred; maximal transdiaphragmatic pressure was $90 \pm 27 \mathrm{cmH}_{2} \mathrm{O}$. Most morphometric measurements of the diaphragm and external intercostals were within the range of values reported previously in other skeletal muscles. The size of the fibres of these two respiratory muscles was positively related $(\mathbf{p}<0.05)$ to MIP $(\%$ pred $)$. There were no significant relationships between the structure of both muscles and nutritional status or any index of lung function.

In conclusion, in the population studied, the fibre size of the diaphragm and external intercostals appears to relate to their ability to generate force.

Eur Respir J 1998; 11: 906-911.

\begin{abstract}
* Servei de Pneumologia, Hospital Univ. Son Dureta, Universita Illes Balears, Palma de Mallorca, Spain. **Servei de Pneumologia i Grup de Recerca de Pneumologia +Servei di Anatomia-Patològica and Servei Cirugia Toràcica, Hospital del Mar and IMIM, Universitat Autònoma de Barcelona, Barcelona, Spain.
\end{abstract}

Correspondence: J. Sauleda, Servei de Pneumologia, Hospital Universitari Son Dureta, C/Andrea Doria No. 55, Palma de Mallorca, 07014, Balears, Spain, Fax: 3471 175130

Keywords: Diaphragmatic function maximal inspiratory pressure morphometry

respiratory muscles

Received: November 151996

Accepted after revision November 171997

Presented at the European Respiratory Society meeting held in Nice in 1994.

Supported, in part, by FISS 92/0314, ABEMAR, CIRIT AR/91/-367 and IMIM 1642380
Respiratory muscle dysfunction is a well recognized cause of respiratory failure [1-3]. In clinical practice, the function of the respiratory muscles are usually assessed by measuring maximal inspiratory and expiratory pressures (MIP and MEP, respectively) [3] and sometimes, by evaluating mean transdiaphragmatic pressure $(P \mathrm{di})$ [4]. Yet, the structural basis of these measurements (i.e., the relationship between these functional indices and the structure of the respiratory muscles) has not yet been established, particularly for the diaphragm, which functionally is the most relevant respiratory muscle [1-3]. The main aim of this investigation was to evaluate potential relationships between the structure of the diaphragm (and external intercostals) and several indices of respiratory muscle function commonly used in practice. Because there is only one previous study in this field that related the structure of the external intercostals to a limited number of physiological variables [5], the latter group of muscles was also evaluated.

Finally, how the structure of these two respiratory muscles (diaphragm and external intercostals) relate to several indices of lung function and some nutritional variables was also investigated. This topic has been studied previously [6-10], but because of its potential clinical rele- vance, further investigation complement and extend knowledge based on previously published data was required.

\section{Materials and methods}

Study subjects

A total of 27 consecutive eligible patients with localized lung cancer, who required a thoracotomy were studied. To avoid potential confounding effects upon muscle structure, patients with neuromuscular disorders, cardiac failure diabetes mellitus, alcoholism, and/or those who were receiving treatment with steroids [11-15] were excluded. Only males were included in the study because gender has a direct influence upon muscle structure [16]. All patients gave informed consent after full explanation of the nature of the study. The study was approved by the local Ethics Committee of the hospital.

\section{Study design}

Patients with a localized lung neoplasm requiring a thoracotomy were recruited prospectively. In these patients 
lung function and respiratory muscle function were measured and nutritional status assessed prior to surgery. Biopsies $(1.5 \times 1.0 \times 0.5 \mathrm{~cm})$ of the costal diaphragm and the fifth external intercostal at the level of posterior axiliary line were obtained during surgery. Biopsies were immediately frozen in isopentane cooled with liquid nitrogen, and stored at $-70^{\circ} \mathrm{C}$ until analysis (see below).

\section{Methods}

The nutritional status of the patients was assessed using the body mass index $\left(\mathrm{BMI}, \mathrm{kg} \cdot \mathrm{m}^{-2}\right)$, percentage of ideal body weight (IBW) [17], lean body mass (LBM, kg) calculated from the prediction equation of Eddy [18] (percentage of fat for males $=(1.281 \times \mathrm{BMI})-10.13))$ and several biochemical variables, such as total serum protein $\left(\mathrm{g} \cdot \mathrm{dL}^{-1}\right)$ and serum albumin $\left(\mathrm{g} \cdot \mathrm{dL}^{-1}\right)$. Forced spirometry (Datospir92, Sibel, Barcelona, Spain), static lung volumes and airway resistance by body plethysmography (Masterlab, Jaeger, Würzburg, Germany), single breath transfer factor of the lung for carbon monoxide (TL,CO) (Jaeger) and arterial blood gases (ABL 330; Radiometer, Copenhagen, Denmark) were measured $48-72 \mathrm{~h}$ prior to surgery with the subjects in the sitting position. Spirometric, TL,CO and lung volume reference values were obtained from a mediterranean population [19-21]. Respiratory muscle function was assessed by measuring: 1) MIP at the mouth against an occluded airway (Sibelmed-163; Sibel, Barcelona, Spain), using the method described originally by B BaCK and HyatT [22]. MIP was analysed in absolute values and as percentage of predicted values [22]; 2) mean $P$ di: oesophageal $\left(P_{\text {oes }}\right)$ and gastric $(P$ ga $)$ pressures were obtained using balloon catheters (Jaeger) coupled to pressure transducers (Transpac II; Abbot, Chicago, IL, USA) and connected to a polygraph (Beckman R-6; Sensorsmedics, Anaheim, CA, USA). The balloons were calibrated over appropriate pressure ranges at the beginning and end of each study. The oesophageal balloon containing 0.5 $\mathrm{mL}$ of air was positioned in the mid oesophagus. The gastric balloon contained $1 \mathrm{~mL}$ of air. $P$ di was taken as the difference between mean $P$ ga and mean $P_{\text {oes, }}$, while the patient was seated during tidal breathing [23]; and, 3) maximal transdiaphragmatic pressure $(P$ di,max $)$ was assessed during a sniff manoeuvre $(P$ di,sniff $)$ [24]. The highest $P$ di,sniff value of five different manoeuvres was chosen for analysis.

Sections of the diaphragm and external intercostals were cut $6 \mu \mathrm{m}$ thick in a cryostat $\left(-20^{\circ} \mathrm{C}\right)$. Type I ("slow twitch") and type II ("fast twitch") fibres were identified by the standard adenosine triphosphatase (ATPase) (at 9.4 and $4.6 \mathrm{pH}$ pre-incubation) (fig. 1), and reduced nicotinamine adenine dinucleotide tetrazolium (NADH-TR) stains [25, 26]. Morphometric evaluation was done using a semiautomatic system (Videoplan 2, Zeiss, Kontron electronics, Bremen, Germany). Measurements, performed independently by two different observers, included quantitation of: 1) percentage of type I and II fibres; 2) least fibre diameter for each fibre type (this diameter is minimally influenced by the cutting angle during sample process) [25]; and 3) atrophy and hypertrophy index (AI and $\mathrm{HI}$, respectively), calculated using the method of BROOKE and Engel [26]. These two indices evaluate, respectively, the two tails of the least diameter histogram of at least 100

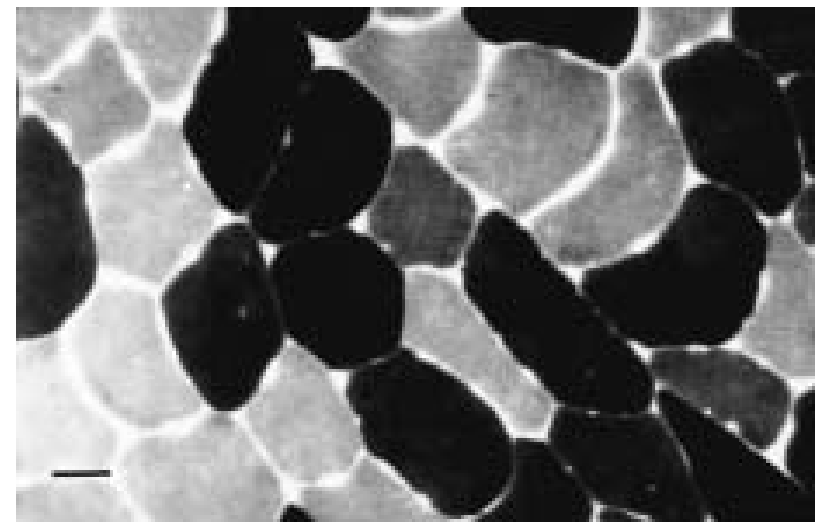

Fig. 1. - Adenosine triphosphatase (ATPase) stain ( $\mathrm{pH} 9.4$ ) from a representative diaphragmatic sample. Type I fibres are stained clear and type II fibres are stained dark. Internal scale bar $=100 \mu \mathrm{m}$.

muscle fibres. To calculate the AI a category is assigned to each measured fibre, such that normal fibres $(40-80 \mu \mathrm{m}$ in diameter) are rated 0 , intermediate fibres rated 1 and 2 and the smallest fibres rated 3 . The AI is derived by summing the values in each category, divided by the total number of fibres in the histogram, and multiplied by 1,000 . The larger this index, the greater the degree of atrophy. A separate HI was calculated for each specimen, using a similar scale for fibres larger than $80 \mu \mathrm{m}$. Values $>250$ were considered abnormal $[6,8]$.

\section{Statistical analysis}

Data are presented as mean \pm SD and range. The reproducibility of the morphometric measurements between the two observers was tested using the intraclass correlation coefficient [27]. Potential relationships between structure and function of the respiratory muscles, lung function and nutritional status were evaluated using the Pearson's linear correlation coefficient. The results of the morphometric analysis were compared in patients with and without airflow obstruction, the latter being defined as an forced expiratory volume in one second (FEV1)/forced vital capacity (FVC) ratio $<70 \%$ and $\mathrm{FEV} 1<70 \%$ pred, using the Mann-Whitney test. The level of significance was assessed after correction for multiple comparisons (Bonferroni).

\section{Results}

The mean age of the 27 patients studied was $61 \pm 10$ yrs of age. No patient was grossly undernourished. Mean BMI was $24.4 \pm 2.76 \mathrm{~kg} \cdot \mathrm{m}^{-2}$, IBW $111 \pm 12 \%$ pred, and LBM $60 \pm 3 \mathrm{~kg}$. Mean serum albumin was $3.9 \pm 0.6 \mathrm{~g} \cdot \mathrm{dL}^{-1}$ and mean total serum protein was $6.8 \pm 0.9 \mathrm{~g} \cdot \mathrm{dL}^{-1}$. On average, patients showed mild airflow limitation (with some air trapping) and normal gas exchange (table 1), but some individuals had moderate to severe airflow obstruction and mild hypoxaemia. On average MIP was slightly reduced $(77 \pm 25 \%$ pred). Seven patients showed an MIP value $<65 \%$ pred (table 2$)$. Mean maximal $P_{\text {oes }}\left(P_{\text {oes, }}\right.$ max $)$ $\left(64 \pm 18 \mathrm{cmH}_{2} \mathrm{O}\right)$ and $P$ di,max $\left(90 \pm 27 \mathrm{cmH}_{2} \mathrm{O}\right)$ (table 2) were slight-ly lower than previously published in healthy subjects [28]. 
Table 1. - Indices of lung function

\begin{tabular}{lcc}
\hline & Mean \pm SD & Range \\
\hline FEV1 \% pred & $70 \pm 14$ & $44-96$ \\
FEV1/FVC \% & $70 \pm 9$ & $45-79$ \\
RV \% pred & $139 \pm 50$ & $75-254$ \\
$T \mathrm{~L}, \mathrm{CO} \%$ pred & $82 \pm 16$ & $47-119$ \\
$\mathrm{~Pa}_{2} \mathrm{O}_{2} \mathrm{kPa}$ & $11.3 \pm 1.3$ & $8.6-13.6$ \\
$P_{\mathrm{a}, \mathrm{CO}_{2}} \mathrm{kPa}$ & $5.5 \pm 0.5$ & $4.4-6.3$ \\
$P \mathrm{~A}-\mathrm{a}, \mathrm{O}_{2} \mathrm{kPa}$ & $1.9 \pm 1.2$ & $0-4.4$ \\
\hline
\end{tabular}

FEV1: forced expiratory volume in one second; \% pred: percentage of predicted value; FVC: forced vital capacity; RV: residual volume; TL,CO: transfer factor of the lung for carbon monoxide; $\mathrm{Pa}, \mathrm{O}_{2}$ : arterial oxygen tension; $P \mathrm{a}, \mathrm{CO}_{2}$ : arterial carbon dioxide tension; $P \mathrm{~A}-\mathrm{a}, \mathrm{O}_{2}$ : alveolar-arterial pressure difference for oxygen. $1 \mathrm{kPa}=7.52 \mathrm{mmHg}$.

Table 2. - Indices of respiratory muscle function

\begin{tabular}{lcc}
\hline & Mean \pm SD & Range \\
\hline MIP \% pred & $77 \pm 25$ & $26-137$ \\
$P$ di $\mathrm{cmH}_{2} \mathrm{O}$ & $6 \pm 2.5$ & $2.6-11$ \\
$P_{\text {oes, } m a x} \mathrm{cmH}_{2} \mathrm{O}$ & $64 \pm 17$ & $27-108$ \\
$P_{\mathrm{di}, \max } \mathrm{cmH}_{2} \mathrm{O}$ & $90 \pm 27$ & $45-172$ \\
$P$ di $/ P$ di, $\max$ & $0.08 \pm 0.05$ & $0.03-0.22$
\end{tabular}

MIP: maximal inspiratory pressure; $\%$ pred: percentage of predicted value; $P$ di: mean transdiaphragmatic pressure; $P_{\text {oes,max: }}$ maximal oesophageal pressure; $P$ di,max: maximal transdiaphragmatic pressure.

Morphometric measurements were highly concordant between the two observers $(\mathrm{r}=0.9)$. On average, the different morphometric indices evaluated in both muscles (table 3 ) were within the range of values previously reported in healthy subjects in other skeletal muscles [29], but some patients showed an $\mathrm{HI}$ in the diaphragm $>250$, which is clearly abnormal $[6,8]$. We found no significant differences between the morphometric variables of patients with and without airflow obstruction, as defined above.

The relationships between the structure and function of the two respiratory muscles evaluated in this study are shown in figures 2 and 3. MIP (\% pred) was significantly related to the diameter of: 1) type I and type II diaphragmatic fibres (fig. 2); and 2) type II fibres of the external intercostals (fig. 3). Pdi,max showed no correlation with muscle

Table 3. - The structural parameters of the different muscles

\begin{tabular}{lcc} 
Fibres & Diaphragm & External intercostals \\
\hline Type I \% & $56 \pm 9$ & $62 \pm 10$ \\
& $(41-77)$ & $(40-76)$ \\
Type II \% & $44 \pm 9$ & $38 \pm 10$ \\
& $(23-59)$ & $(24-60)$ \\
Type I+ $\mu \mathrm{m}$ & $64 \pm 9$ & $60 \pm 8$ \\
& $(45-81)$ & $(47-79)$ \\
Type II ${ }^{+} \mu \mathrm{m}$ & $61 \pm 12$ & $57 \pm 8$ \\
& $(45-84)$ & $(44-74)$ \\
Type I AI & $52 \pm 70$ & $69 \pm 81$ \\
& $(0-300)$ & $(0-240)$ \\
Type II AI & $120 \pm 134$ & $157 \pm 200$ \\
& $(0-500)$ & $(0-700)$ \\
Type I HI & $345 \pm 404$ & $170 \pm 278$ \\
& $(0-1560)$ & $(0-1000)$ \\
Type II HI & $364 \pm 465$ & $78 \pm 150$ \\
& $(0-1530)$ & $(0-520)$ \\
\hline
\end{tabular}

Values are presented as mean \pm SD with range in parenthesis. ${ }^{+}$: least diameter. AI: atrophy index; HI: hypertrophy index.
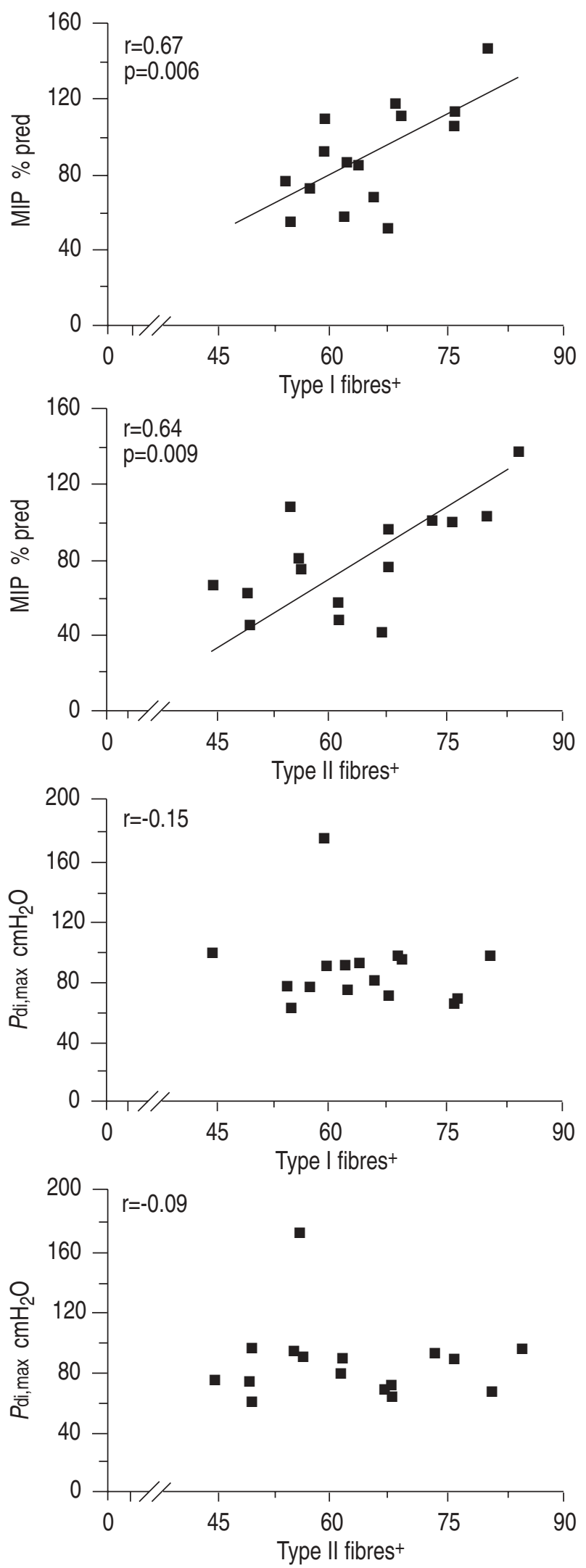

Fig. 2. - The relationships between morphometric parameters of the diaphragm and indices of respiratory muscle function using Bonferroni multiple comparisons. MIP: maximal inspiratory pressure; \% pred: percentage of predicted value; $P$ di,max: maximal transdiaphragmatic pressure. +: least diameter. 

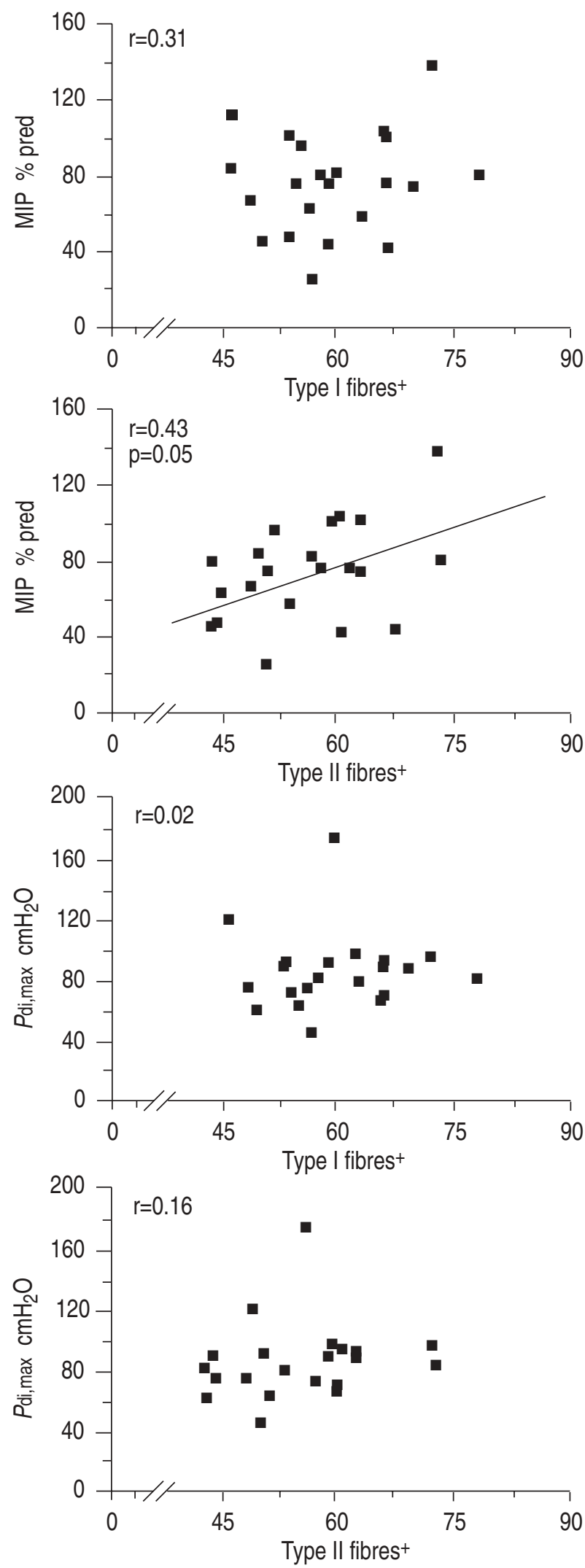

Fig. 3. - The relationships between morphometric parameters of the external intercostals and indices of respiratory muscle function using Bonferroni multiple comparisons. MIP: maximal inspiratory pressure; $\%$ pred: percentage of predicted value; $P$ di,max: maximal transdiaphragmatic pressure. +: least diameter.
Table 4. - The relationship between nutritional indices and muscle morphometry using Bonferroni multiple comparisons

\begin{tabular}{lrcrr}
\hline & $\begin{array}{c}\text { BMI } \\
\mathrm{kg} \cdot \mathrm{m}^{-2}\end{array}$ & $\begin{array}{c}\text { Total serum } \\
\text { protein } \mathrm{g} \cdot \mathrm{dL}^{-1}\end{array}$ & $\begin{array}{r}\text { IBW } \\
\%\end{array}$ & \multicolumn{1}{c}{$\begin{array}{c}\mathrm{LBM} \\
\mathrm{kg}\end{array}$} \\
\hline Diaphragm & & & & \\
Type I $+\mu \mathrm{m}$ & 0.36 & 0.64 & 0.39 & 0.12 \\
Type II+ $\mu \mathrm{m}$ & 0.52 & 0.34 & 0.53 & 0.19 \\
Type I AI & -0.28 & -0.25 & -0.26 & -0.02 \\
Type II AI & -0.51 & -0.25 & -0.50 & -0.21 \\
Type I HI & 0.28 & 0.35 & 0.25 & 0.49 \\
Type II HI & 0.30 & 0.15 & 0.26 & 0.28 \\
External & & & & \\
intercostals & & & & \\
Type I + $\mu \mathrm{m}$ & 0.17 & 0.44 & 0.19 & 0.07 \\
Type II $\mu \mathrm{m}$ & 0.31 & 0.41 & 0.30 & 0.13 \\
Type I AI & -0.09 & -0.53 & -0.13 & -0.01 \\
Type II AI & -0.08 & -0.28 & -0.10 & 0.01 \\
Type I HI & 0.28 & 0.33 & 0.27 & 0.22 \\
Type II HI & 0.28 & 0.24 & 0.25 & 0.21 \\
\hline BMI body mas & & & &
\end{tabular}

BMI: body mass index; IBW: ideal body weight; LBM: lean body mass; +: least diameter; AI: atrophy index; HI: hypertrophy index.

morphometry (figs. 2 and 3). Other measurements of diaphragmatic function $P \mathrm{di}, P_{\mathrm{oes}}$,max and $P \mathrm{di} / P_{\mathrm{di}}$,max showed no correlation either. No correlations between any indices of muscle structure and lung function were found. By contrast, several nutritional variables appeared to be related to muscle structure (table 4), although after correcting for multiple comparisons (Bonferroni), the p-values did not reach the required level of statistical significance $(\mathrm{p}<$ 0.001).

\section{Discussion}

Although the diaphragm is an important component of the respiratory system, there is a surprising paucity of data about the relationship between its structure and function in humans. A significant relationship between its fibre size and MIP was observed (fig. 2). It was surprising though, that more specific indices of diaphragmatic function $(P \mathrm{di}, P$ oes,max, $P$ di,max and $P \mathrm{di} / P$ di,max $)$ were not correlated with the morphometric variables assessed. The lack of correlation has several possible explanations. Firstly, the lack of available reference values for $P_{\mathrm{di}}$ max and $P$ oes,max may have jeopardized an ability to disclose potential structure-function relationships. In fact, a relationship with MIP was only found when results were expressed as percentage of predicited value (fig. 2), but not when expressed as absolute values. Secondly, diaphragmatic function is in-fluenced by a number of factors, such as fibre type, num-ber of capillaries and mitochondria and oxygen delivery to tissues, among others [1], that were not directly assessed in our study. It is conceivable that the use of the morphometric indices, such as fibre volume, mitochondrial density, length and/or number of sarcomere, would have given different results, as recently shown in another, as yet preliminary study [30]. Finally, it is thought that methodo-logical errors in the morphometric analyses are unlikely because similar methods to those reported in previous stu-dies [5-11] were used and the morphometric measurements were highly concordant between the two observers. 
Only one previous study has related the structure of the external intercostals to MIP [5]. This study failed to show any significant correlation [5]. In contrast, a weak but significant relationship between fibre size of the external intercostals and MIP was observed in the present study, as was also observed in the diaphragm samples of the patients (fig. 3). This apparent discrepancy with previous studies might be explained by the careful selection of subjects in our investigation. In particular, only male subjects (sex has some effects upon muscle structure [16]) were included, and patients with diseases known to influence muscle structure, excluded. This selection and, perhaps also ethnic differences, might also explain the observation of a higher fibre size of the external intercostals than those previously reported $[5-8,10]$. An effect of the neoplasm itself upon muscle structure, cannot be completely discounted but this limitation is shared by most previous studies of respiratory muscle structure in humans [5-10].

Some studies have reported significant relationships between muscle structure and nutrition $[5,31]$ while others failed to show them [6-8]. It was found (table 4) that some nutritional indices appeared to be related to muscle structure, but the correlation coefficients failed to reach statistical significance. This is probably due to the absence of overt malnutrition in any of the patients studied, as shown by the normal values of BMI, IBW and total serum protein. Thus, the results suggest that the effect of nutrition on respiratory muscle structure is small in this population (patients submitted to thoracotomy for a lung neoplasm). Similarly, no significant relationships between the structure of the diaphragm (or the external intercostals) and various indices of lung function were found. Previous studies have reported similar results $[5-7,10]$. The relatively narrow range of lung function values in these patients subjected to thoracotomy may also help to explain the lack of relationships observed. However, it is interesting to note that fibre type and fibre size were not different according to the presence or absence of airflow obstruction again in keeping with previous studies [5-7, 10].

In summary, this is the first study assessing possible relationships between the structure of the diaphragm and several indices of respiratory muscle function, lung function and nutrition in humans. A direct correlation between the size of the diaphragmatic fibres and maximal inspiratory pressure was found, but no significant relationships between muscle structure and lung function or several nutritional indices were found. Perhaps, future studies in patients with advanced chronic obstructive pulmonary disease, undergoing lung volume reduction surgery would provide an opportunity to obtain diaphragmatic samples. This would provide a means of assessing, potential remodelling of the diaphragm due to chronic airflow limitation [32].

Acknowledgements: The authors would like to thank M. Trenchs and N. Soler for the technical assistance.

\section{References}

1. Rochester DF, Arora NS. Respiratory muscle failure. Med Clin North Am 1983; 67: 573-599.

2. Derenne JP, Macklem PT, Roussos C. The respiratory muscles: mechanics, control, and pathophysiology. Am Rev Respir Dis 1978; 118: 581-601.

3. Belman MJ, Sieck GC. The ventilatory muscles. Chest
1982; 82: 761-766

4. Murciano D, Auclair MH, Pariente R, Aubier, M. A randomized, controlled trial of theophylline in patients with severe chronic obstructive pulmonary disease. $N$ Engl $J$ Med 1989; 320: 1521-1525.

5. Hards JM, Reid WD, Pardy RL, Paré PD. Respiratory muscle fibre morphometry. Chest 1990; 97: 1037-1044.

6. Campbell JA, Hughes RL, Sahgal V, Frederiksen J, Shields TW. Alterations in intercostal muscle morphology and biochemistry in patients with obstructive lung disease. Am Rev Respir Dis 1980; 122: 679-686.

7. Hughes RL, Katz H, Sahgal V, Campbell JA, Hartz R, Shields TW. Fibre size and energy metabolises in five separate muscles from patients with chronic obstructive lung disease. Respiration 1983; 44: 321-328.

8. Sanchez J, Derenne JP, Debesse B, Riquet M, Monod H. Typology of the respiratory muscles in normal men and in patients with moderate chronic respiratory diseases. Bull Europ Physiopath Resp 1982; 18: 901-914.

9. Sanchez J, Brunet A, Medrano G, Debesse B, Derenne JP. Metabolic enzymatic activities in the intercostal and serratus muscles and in the latissimus dorsi in middle-aged normal men and patients with moderate obstructive pulmonary disease. Eur Respir J 1988; 1: 376-383.

10. Mizuno M, Secher NH, Saltin B. Fibre types, capillary supply and enzyme activities in human intercostals muscles. Clin Physiol 1985; 5: 121-135.

11. Stern LZ, Payne CM, Gruener R, Anderson RM, Hannapel LK. Intercostal muscle biopsy in human neuromuscular disease. J Neurol Neuros Psych 1975; 38: 900-910.

12. Cardellach F, Galofré J, Grau JM, et al. Oxidative metabolism in muscle mitochondria from patients with chronic alcoholism. Ann Neurol 1992; 31: 515-518.

13. Wanke T, Formanek D, Auinger M, et al. Mechanical load on the inspiratory muscles during exercise hyperpnea in patients with Type 1 (insulin-dependent) diabetes mellitus. Diabetologia 1992; 35: 425-428.

14. Sullivan MJ, Grenn HJ, Cobb FR. Skeletal muscle biochemistry and histology in ambulatory patients with longterm heart failure. Circulation 1990; 81: 518-527.

15. Vignos P, Greene R. Oxidative respiration of skeletal muscle in experimetal corticosteroids myopathy. J Lab Clin Med 1973; 81: 365-378.

16. Glenmark B. Skeletal muscle fibre types, physical performance, physical activity and attitude to physical activity in women and men. A follow-up from age 16-27. Acta Physiol Scand 1994; 151 Suppl. 623: 1-42.

17. Alaustré A, Sitges S, Jaurrieta M, Sitges C. Valoración de los parámetros antropométricos en nuestra población. Med Clin 1982; 78: 407-415.

18. The working Party. Obesity. A report of the Royal College of Physicians, table 14, p 26. J R Coll Physicians Lond 1983; 17: 5-65.

19. Roca J, Sanchis J, Agustí-Vidal A, et al. Spirometric reference values for a mediterranean population. Bull Eur Physiopathol Respir 1986; 22: 217-224.

20. Roca J, Burgos F, Barberá JA, et al. Prediction equations for plethysmographic lung volumes. Respir Med (In press).

21. Roca J, Rodríguez-Roisín R, Cobo E, Burgos F, Pérez J, Clausen JL. Single-breath carbon monoxide diffusing capacity (DLco) prediction equations for a mediterranean population. Am Rev Respir Dis 1990; 141: 1026-1032.

22. Black LF, Hyatt RE. Maximal respiratory pressures: normal values and relationship to age and sex. Am Rev Respir Dis 1969; 99: 696-702.

23. Laporta D, Grassino A. Assessment of transdiaphrag- 
matic pressure in humans. Am J Physiol 1985; 58: 1469 1476.

24. Mier A. Respiratory muscle weakness. Resp Med 1990; 84: 351-359.

25. Dubowitz V, Brooke MH. Histological and histochemical stains and reactions. In: Dubowitz V, Brooke MH eds. Muscle biopsy: a modern approach. London, WB Saunders Company Ltd, 1973: pp. 20-33.

26. Brooke MH, Engel WK. Histographic analyses of human muscle biopsies with regard to fibre types I. Neurology 1969; 19: 221-233.

27. Bland JM, Altman DG. Statistical methods for assessing agreement between two methods of clinical measurement. Lancet 1986; i: 307-310.

28. Laroche CM, Mier A, Moxham J, Green M. The value of sniff esophageal pressures in the assesment of global inspiratory muscle strength. Am Rev Respir Dis 1988; 138: 598-603.

29. Bennington JL, Krupp M. Morphometric analysis of muscle. In: Heffner, RR ed. Muscle pathology. New York, Churchill Livingstone, 1984; pp. 43-72.

30. Orozco M, Gea J, Lloreta J, Aguar MC, Serrano S, Broquetas JM. Mitochondria in the human diaphragm and pulmonary function. Am Rev Respir Dis 1994; 149: A325.

31. Arora NS, Rochester DF. COPD and human diaphragm muscle dimensions. Chest 1987; 91: 719-724.

32. Gea J, Hamid Q, Comtois N, Salazkin I, Goldspink G, Grassino A. mRNA expression of slow heavy chain myosin of diaphragm increases following resistive breathing. Am J Respir Crit Care Med 1996; 153: A294. 